\title{
Article
}

\section{Prospective ongoing prescribing error feedback to enhance safety: a randomised controlled trial}

Gordon, Morris and Jones, Helen Laura

Available at http://clok.uclan.ac.uk/18343/

Gordon, Morris ORCID: 0000-0002-1216-5158 and Jones, Helen Laura (2017) Prospective ongoing prescribing error feedback to enhance safety: a randomised controlled trial. Drugs and Therapy Perspectives . pp. 1-8. ISSN $1172-0360$

It is advisable to refer to the publisher's version if you intend to cite from the work. http://dx.doi.org/10.1007/s40267-017-0412-z

For more information about UCLan's research in this area go to http://www.uclan.ac.uk/researchgroups/ and search for < name of research Group>.

For information about Research generally at UCLan please go to http://www.uclan.ac.uk/research/

All outputs in CLoK are protected by Intellectual Property Rights law, including Copyright law. Copyright, IPR and Moral Rights for the works on this site are retained by the individual authors and/or other copyright owners. Terms and conditions for use of this material are defined in the policies page.

\section{CLoK}

Central Lancashire online Knowledge www.clok.uclan.ac.uk

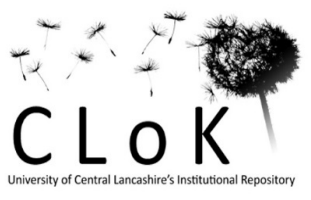




\title{
Prospective ongoing prescribing error feedback to enhance safety: A randomised controlled feasability trial
}

Morris Gordon $\mathrm{PHD}^{1,2}$, Helen Jones BPharm ${ }^{3,4}$

1. Families division, Blackpool Teaching Hospitals NHS Foundation Trust, Blackpool, UK

2. School of Medicine, University of Central Lancashire, Preston, UK

3. Pharmacy department, Blackpool Victoria Hospital, Blackpool, UK

4. School of Pharmacy, University of Central Lancashire, Preston, UK

Corresponding Author: Dr Morris Gordon

\author{
Harrington building HA118, \\ University of central Lancashire \\ Preston, \\ PR1 2HE \\ Email: mgordon@uclan.ac.uk \\ Phone ++447816 687791
}

Word Count:

Keywords: Patient safety, error, prescribing, feedback, Education,

Ethical Approval: Approved by National REC through Research and development department

Competing Interests: None to declare

Funding: Research and development pump priming grant $£ 6900$, Blackpool Victoria Hospital

Word count: 2989 


\section{Abstract}

Background: Prescribing errors are one of the most common adverse events in healthcare. Previous research in patient safety has highlighted the importance of error awareness education to enhance professional attitudes and reduce errors. Systems of contemporaneous prescribing feedback previously researched are limited by shift working. A pilot study investigating a ward specific system of prospective ongoing prescribing error feedback to prescribers led to a significant reduction in errors. This study will investigate the systems introduction over several wards to reduce errors.

Methods: A Cluster randomised controlled tria in a UK teaching hospital, UK. All medical prescribing staff in 4 inpatient ward areas. After each ward prescribing assessment, a ward specific feedback document was prepared, giving general and anonymous feedback and forwarded to all consented participants in the intervention areas. Primary outcome was total prescribing error rates, secondary outcome measures included clinical error rates, technical error rates and cost per error prevented.

Results: 1493 medication orders were assessed for errors. There was no difference in error rates at baseline (32.4\% vs $42.6 \% \mathrm{p}=0.594$ ). After the introduction of the prospective ongoing prescribing error feedback, there was significant difference in the overall rates of error $(64.8 \%$ vs $26.3 \% \mathrm{p}=0.003)$. Similarly, there were statistically significant differences in the rates of clinical error $(p=0.003)$ and technical error $(\mathrm{p}=0.013)$ on completion. The modelled cost of errors prevented in the intervention wards was $£ 2.56$ per error.

Conclusions: A simple process of prescribing error feedback, grounded in non-technical skills educational theory, reduces prescribing errors within a hospital setting. This system is cost effective as well as requiring minimal resource to instigate.

\section{Key Points}

After the introduction of the prospective ongoing prescribing error feedback, there was significant difference in the overall rates of error between intervention and control wards. This process is grounded in non-technical skills and human factors theory, allowing replication in a context specific manner by readers. This system is cost effective as well as requiring minimal resource to instigate. 


\section{Background}

In a key report two decades ago, it was estimated that prescribing errors kill 7000 patients a year in the USA [1]. Large prevalence based projects in the UK have demonstrated startling consistency in rates of error at over 10\% of medication orders [2,3] and reporting data suggests over 190,000 medication errors occurred within the last 12 months in England and Wales [4].

Medication error improvement programmes have been of great interest, tending to focus on one of two main strategies: education or system based safety processes. Education on enhancing knowledge and skills [5] have failed to demonstrate improvements within the workplace [6]. Whilst lack of knowledge and skills contribute, medication errors are multifactorial, with several active failures and errorprovoking human factors involved [6, 7].

The majority of health care professionals are familiar with the concept of 'human factors'. Human factors engineering is a branch of work from psychology that is often misunderstood and seen as synonymous with systems based improvement strategies. In other industries this is often true, but within the complex healthcare environment, engineering systems to prevent human error is almost impossible [8]. This explains whilst the alternative approach to medication error reduction, systems based approaches, have been limited in their success $[9,10]$. These merely shift the area where error can and will occur, which still takes place at the so called 'man-machine' interface [10]. Indeed, whilst there is a current NHS England drive towards electronic order entry, ongoing research confirms that errors can and still do occur, with merely the type changing [11].

Extensive work in high stakes industries as early as the 1970s demonstrated that improving safety is not just about the right technical skills or systems, but addressing human factors (non-technical skills) amongst professionals that lead to error [12]. The airline industry found that many crashes were due to failures of interpersonal communication, decision making and leadership amongst the crew [13]. Programs that recognised these human factors were designed to modify behaviour and this led to crew resource management training [14]. As such work is focused on the worker at the 'sharp end' of errors, this sort of training would seem to be a useful compliment to existing system based patient safety improvement strategies.

A small area of human factors that has achieved much interest from educators is that of non-technical skills: the social (communication and team work) and cognitive (analytical and personal behaviour) skills that play a vital role in the support of high- quality, safe, and effective care [15]. Non-technical skills can form a focus for education that offers more than simply training and re-training, as well as supporting the safer use of other system based approaches by reducing the risk of error at the 'manmachine’ interface [16], they represent an intriguing strategy for medication error improvement. 
A theoretically grounded educational model of non-technical skills learning has been developed through the consideration of key safety issues, such as prescribing, the SECTORS model [17] (Systems and technology use, Error awareness, Communication, Teamworking, Observation and simulation, Risk assessment and Situational awareness) and has been applied to a programme of medication safety improvement [6]. The key to this model is error awareness and enhanced error wisdom, which have also previously been applied to medication error improvement works. In this context, the' 'agency problem' is discussed, where doctors evade their professional responsibility [18] in settings of discontinuity or where the ability of patients to accurately assess the professional's performance in a task is limited. This would seem particularly relevant in the context of prescribing.

A ward round based 'check and correct' system in line with these models that provides medication error feedback has been piloted [19] and implemented [20] with reductions in errors noted. The educational strength of such a system is that by bringing discussions of error into the workplace, it is in line with a situated cognition model of education [21] and therefore tackles the 'agency problem'. However, check and correct does have some limitations due to the workload associated with the system, difficulties in getting feedback to the appropriate individuals who works shifts and the fact that the whole cohort of medical staff do not benefit from each piece of feedback.

We have previously developed and piloted a system of prospective, ongoing prescribing error feedback [22]. This system uses interrupted audits of medication errors and provides written feedback that is individualised to the area in which it is found and relates error to clinical outcomes. Significant reductions in prescribing errors were seen.

Our objective in this study was to evaluate the efficacy of a similar system within several ward areas of a hospital using a cluster randomised controlled trial design. 


\section{Methods}

\section{Study design}

A cluster randomised controlled trial. Local research and development department and training deanery approval was received, as well as NHS Research Ethical approval through the local research department administered IRAS ethics system. Randomisation was completed used a computer generated random number list. Allocation was concealed using sealed opaque envelopes, with assignment to the next sealed envelope as per the random number list.

\section{Sample size calculations}

The number of clusters was fixed at four ward areas, two in each group. The previous pilot study [22] was used to make a individual randomised sample size estimate of 48 per group at a $90 \%$ power. A previously published formula for cluster sample size [23] was applied and this indicated a minimum number of 36 medication orders per cluster would be needed to detect a similar reduction in prescribing errors.

\section{Setting}

The study took place in a teaching hospital offering acute and community services to a population of 1.6 million. Four inpatient wards were purposefully selected for inclusion in the study: A children’s ward, an orthopaedic ward, an endocrine ward and a cardiology ward. These were selected as they represent a range of clinical specialisms, as well as all having almost mutually exclusive clinical teams, with the aim of preventing contamination. Whilst consideration was given to randomizing specific staff, the same concerns regarding this issue of contamination within study areas led to the cluster design.

All medical staff who prescribe in each of these clinical areas were contacted by email, at departmental meetings and through on-ward recruitment over an 8-week period March-April 2016. They were offered a participant information leaflet and then if they wished to take part, gave written consent. As the data being collected formed part of routine prescribing safety monitoring, it was explained that participants were only consented for additional feedback. Involvement in the trial would not impact on the routine audit, quality assurance and intervention processes conducted by the pharmacists.

\section{Pilot period}

During the 8 week consenting period, ward pharmacists in each of the study began collecting data using a bespoke electronic pro-forma, with several changes made to the interface and content based on 
feedback. A senior pharmacist acting as principle investigator performed reliability checks during this period to confirm the appropriate and consistent recording of data. The error data was aligned with the previous published EQUIP trial [2], in which this hospital participated for data collection.

The pharmacists in each of the ward areas reviewed the inpatient prescription charts as per normal procedure. In addition, they documented all technical and clinical errors directly onto a bespoke database. They used the Trusts prescribing policy to inform their decision of whether an error was technical and their expertise and appropriate texts to determine clinical error. All intervention on the ward by the pharmacist was maintained as normal during this process. The pilot period allowed for quality assurance checks for the data collection pharmacists and to ensure the database had an appropriate functionality. All inpatient prescriptions were included except oxygen. A baseline assessment of a sample of inpatient prescription charts were reviewed against the trust prescribing policy. Each medication order was assessed against the trust minimum prescribing standards (Table 1), with any breaches noted. Each order could have more than one error. Errors were not recorded if they had been corrected by the prescriber immediately, but were recorded if they had been corrected by other staff.

Table 1. Trust minimum standards for prescriptions

\section{Appendix 1: Minimum acceptable standards for accurate prescription writing}

All prescriptions to be written in indelible black ink

All items on the prescription must be printed in clear \& legible handwriting

All items must be signed

All items must include a legible printed name next to the signature

All items must include a personal bleep number (when available). Not a baton bleep

All items must have a start date

All items must have times of administration to be clearly stated.

All antibiotics items must be written on the Antibiotic Section. The times written as a 24 hour clock e.g. tds as $0600,1400,2000$

All items requiring changes to drug/dose/frequency must be written as a new prescription entry and the previous entry must be crossed off. Do not amend existing prescriptions- start again.

All drugs cancellations must be made with a clear bold line across the drug name and administration sections( without obliterating the patient record)

All cancelled items must have a stop date.

The date of cancellation should be entered in the stop-date box.

When the 'stop date' box is used in anticipation of the treatment cancellation date, this indicates that from midnight on the date specified, the prescription must be discontinued and no further doses are to be administered. A line should be drawn through the administration section to indicate that the prescription should not be given past that date. 
All cancelled items must have a signature

All drugs must be prescribed by their generic names, unless brand name prescribing recommended by the BNF. Common e,g's are beclomethasone inhalers, theophylline, diltiazem,nifedipine,lithium, mesalazine modified-release preparations.

All drug names must be written in full.

All items must include the frequency of administration.

All "additional information" must be clear and unambiguous.

Drug administration device types must be included on the prescription. e.g. inhaler type (e.g. MDI, turbohaler, accuhaler) and insulin type (flexpen. Kwipen etc)

All prescriptions must include the strength of the preparation (where this is necessary)

All items must include the dose and dose units ( where this is necessary)

Only these approved dose unit abbreviations may be used.

$\mathrm{g}$ is accepted for gram

mg for milligram

micrograms to be written in full

nanograms to be written in full.

1 gram or more should be written as $1 \mathrm{~g}, 2.4 \mathrm{~g}$ etc

Less than 1gram should be written in milligrams. 250mg and not $0.25 \mathrm{~g}$

Less than $1 \mathrm{mg}$ should be written in micrograms. 100micrograms and not $0.1 \mathrm{mg}$.

Only use decimal points and zeros if necessary e.g. prescribe $3 \mathrm{mg}$ and not $3.0 \mathrm{mg}$.

$\mathrm{ml}$ is accepted for millilitres.

Caution with liquid formulations. Many different strengths of the same drug can exist or are manufactured. It

is safest for the prescriber to prescribe as the dose and not volume. (Except when there is not a strength e.g.

lactulose, gaviscon)

Caution with "combination" preparations.

The word UNITS must be written in full and not abbreviated to "u" or "i.u."

All PRN medicines prescribed with a drug interval and maximum daily dose

The following types of prescriptions were eligible for assessment, provided they were active on the day of data collection: "once only" drugs, regular medication orders, "when required" drugs and continuous infusions. Discontinued therapies, oxygen, discharge drugs, dietary supplements and antithromboembolism stockings were excluded as were errors corrected by medical before detection by the pharmacist.

This pilot period also allowed an estimate of the additional time taken compared to routine medication order auditing. This was calculated as an extra 15 minutes per hour of auditing.

\section{Procedures and intervention}

Once the study began, audits were completed for a 2-hour period once per week on Wednesday within each of the ward areas. This day was selected as it avoided temporary staff from weekends days of the week when many lieu days are taken resulting in low staffing levels. No audits took place on 
weekends. The pharmacists recorded the number of prescriptions reviewed and submitted a pro-forma on their tablet or lap top for each order with errors encountered. The following day, the Principal investigator ran a report on the database and calculated the percentage of clinical and technical errors reported. Any disagreements in the classification of errors were solved by seeking a third opinion to reach consensus.

After four weeks of baseline data collection during May 2016, randomisation and allocation took place. For the following 10 weeks, a bespoke feedback document was prepared for each of the two intervention areas after the audit data was analysed. This was grounded within the SECTORS model of non-technical skills education [17] and experience using this to design prescribing education [6, 9]. Examples are shown in Figure 1. They were limited to 2 pages of A4, presented as a PDF and grounded in the actual error cases within that area, as well as previous similar error experience within the hospital regarding to give authentic details of potential clinical outcomes. These were sent to all consented prescribers in the intervention ward areas. No feedback was given to the control ward area prescribers.

\section{Outcome measures}

The primary outcome measure was the total rate of prescribing errors, calculated as the number of medical orders with any error as a percentage of the total medication orders audited in all intervention areas compared with control areas.

The secondary outcome measures were the separate rates of clinical error and technical error, calculated similarly. Additionally, financial data was collected based on the audits completed per week and used to calculate the overall cost of the data collection and analysis process during the trial period, as well as the costs per actual error prevented and projected error prevention (assuming the sampled rate of error reduction was consistent amongst all orders).

\section{Data analysis}

Summary statistics were calculated. A two tailed independent sample t-test was used to compare mean rates of error in each of the audits in the control and intervention areas at both baseline (4 weeks) and 7 weeks post intervention (data from the first 3 weeks of the intervention period was not analysed to account for shift patterns and allow all staff to have prescribed and received feedback). Similar analysis was used for the secondary outcomes. Data was analysed in SPSS (Version 22.0. Armonk, NY: IBM Corp.). 


\section{Results}

Consent was obtained from 55 prescribing doctors out of a possible 123 in those areas. No one withdrew consent during the study. During the assessments, a total of 1493 medication orders audited for error were included (Table 2).

Table 2. Raw error data

\begin{tabular}{|c|c|c|c|c|c|c|c|c|c|}
\hline \multirow{2}{*}{$\begin{array}{l}\text { Phase of } \\
\text { study }\end{array}$} & \multirow{2}{*}{$\begin{array}{l}\text { Audit } \\
\text { length }\end{array}$} & \multicolumn{2}{|c|}{ Total orders checked } & \multicolumn{2}{|c|}{ Orders with error } & \multicolumn{2}{|c|}{$\begin{array}{l}\text { Orders with technical } \\
\text { error }\end{array}$} & \multicolumn{2}{|c|}{$\begin{array}{l}\text { Total orders with clinical } \\
\text { error }\end{array}$} \\
\hline & & Control & Intervention & Control & Intervention & Control & Intervention & Control & Intervention \\
\hline Baseline & 4 weeks & 438 & 213 & 58 & 88 & 32 & 82 & 40 & 15 \\
\hline Feedback & 7 weeks & 336 & 506 & 189 & 145 & 154 & 125 & 59 & 39 \\
\hline
\end{tabular}

At baseline during May 2016 there was no statistically significant difference in the rates of error between the control and intervention areas (32.4\% vs $42.6 \% \mathrm{p}=0.594$ ). After the introduction of the prospective ongoing prescribing error feedback, there was significant difference in the overall rates of error in June and July 2016 (64.8\% vs 26.3\% p=0.003). Similarly, there were no statistically significant differences in the rates of clinical and technical prescribing errors at baseline. After introduction of the ongoing prescribing error feedback, there were statistically significant differences in the rates of clinical error $(\mathrm{p}=0.003)$ and technical error $(\mathrm{p}=0.013)$. This data is summarised in Table 3.

Table 3. Rates of error

\begin{tabular}{|c|c|c|c|}
\hline Rates of error & $\begin{array}{l}\text { Control } \\
\text { Mean \% (SD) }\end{array}$ & $\begin{array}{l}\text { Intervention } \\
\text { Mean \% (SD) }\end{array}$ & $\begin{array}{l}\text { P value } \\
(*=\text { sig }<0.05 \\
* * \text { sig }<0.01)\end{array}$ \\
\hline \multicolumn{4}{|l|}{ Baseline } \\
\hline Total Rate & 32.4 (31.7) & $42.6(32.4)$ & 0.594 \\
\hline Technical error rate & $19.8(22.1)$ & 39.7 (32.5) & 0.243 \\
\hline Clinical error rate & $23.2(24.2)$ & $8.0(4.6)$ & 0.16 \\
\hline \multicolumn{4}{|l|}{ Post-intervention } \\
\hline Total Rate & $64.8(34.5)$ & $26.3(21.5)$ & $0.003 * *$ \\
\hline Technical error rate & $56.9(38.0)$ & $22.6(22.3)$ & $0.013 * *$ \\
\hline Clinical error rate & 19.9 (9.3) & $8.0(8.3)$ & $0.003 * *$ \\
\hline
\end{tabular}


2 tailed independent sample t-test

The total cost during the study period for the Lead pharmacist principle investigator and the ward based pharmacist's data collections (based on the increased time needed compared to normal activities) was $£ 3155$ for 10 interventional weeks. Assuming the error rate within the intervention area had not changed from baseline, there would be an extra 82 errors expected in the intervention areas. Therefore, the cost per assessed error prevented was £38. If this reduction in error was modelled throughout the full week of pharmacist medication order reviews, allowing for three sessions of auditing per day during the week, 1230 errors would have been prevented within the two intervention areas, at a cost of $£ 2.56$ per error prevented. 


\section{Discussion}

The prescribing feedback intervention led to a statistically significant difference in prescribing errors when compared to control. This is the first randomised controlled trial to demonstrate such improvements within the workplace, rather than a simulated or assessment environment, raising the prospect of such an intervention significantly impacting patient outcomes. This trial is of substantial size, with 1493 prescribed items assessed, representing 31,000 opportunities for error.

This system allows staff to have intermittent and repeated team based feedback on prescribing within the ward, as well as allowing them to consider areas for improvement in their personal prescribing before harm can befall patients. Moving error and incident reporting from a retrospective and individual level feedback process to a prospective system grounded in non-technical skills education theory [17]. The individualisation of the lessons to department level is aligned with a situated cognition model of learning [21], but allows full teams to learn from such error based lessons.

Previous large scale multi-centre studies investigating errors have been supported by pharmacists collecting data in the manner employed in this study [2]. This suggests a viable and sustainable improvement model, particularly given the costs associated with alternative technology based medication error reduction strategies [24]. As the foundations for data collection are routine pharmacist activities, this approach is logistically viable in many centres. These characteristics render the system simple and quick to implement, as well as limiting the need for any associated significant pump priming costs. Additionally, whilst not identified in this study, the ongoing analysis of data could allow immediate identification of key patterns of prescribing error at an institutional level much earlier than retrospective systems of incident reporting.

Within the range of interventions previously reported in the literature [24], cost is rarely considered. Based on the actual resource involved in the ongoing data collection, analysis and feedback, we have accurately costed this intervention, as well as using this to model the cost per error reduced. This should also allow other centers to consider replicating such an intervention in a manner that is mindful of the likely impact and make informed choices as to the scale of the intervention that they wish to attempt and the cost associated with it.

Despite the promising nature of these results, this study does have several limitations. Even though it was appropriately powered to identify differences in prescribing error rates, given the relatively rarer occurrence of clinical errors or harm to patients, this study hasn't demonstrated impact on these key outcome measures. Additionally, it must be noted that the error rate calculated for this study were different to many other published studies [25]. These studies measure the number of errors that occur as a proportion of the potential opportunities for error. This leads to a denominator that is much greater and a relatively lower percentage error rate. However, it was decided locally that as internal reporting is based on the dichotomous outcome of whether an item was error free or not, this was measured. This 
meant the error rates were relatively higher than are normally reported. Raw data is available to readers on request if required for future research. Whilst the ward areas were selected to represent separate clinical teams, contamination was possible and represents a risk to this and other randomised trials. Finally, whilst this study builds on a growing and theoretically underpinned educational evidence base [6, 17], it has not attempted to assess clarification questions such as how or why the changes occurred.

Future research should examine the feasibility and effectiveness of this intervention if introduced in a variety of settings. This could include impact on other prescribing groups, at other points within the medicine management journey (administration, dispensing) and measurement of other patient outcomes such as critical incident reporting and data returned to the NPSA [4]. Additionally, identification of cost impact at an institutional level would allow commissioners of healthcare to consider the role of this system within their healthcare local providers. Future work could also investigate the introduction of the intervention to address other key sources of error within healthcare, such as transfusions and pathway compliance, as well as its use in other settings such as primary care.

\section{Conclusions}

This cluster randomised controlled trial has demonstrated the effectiveness of prospective ongoing prescribing error feedback to reduce error rates within secondary care. This intervention follows an educational evidence base grounded in non-technical skills and human factors theory. It is cost effective as well as requiring minimal pump priming, utilising on-going ward pharmacist activities to gather data. Future research should consider the impact of institutional level introduction, as well as transference and replication in other settings. 


\section{Competing interest statement}

Authors have all completed the ICMJE disclosure form (uploaded). With the exception of the declared funding, that has been no other financial support for this work, no financial relationships with any organisations that might have an interest in the submitted work in the previous three years, no other relationships or activities that could appear to have influenced the submitted work.

\section{Contributor statement}

Morris Gordon planned the study, analysed the data and led the write up. Helen Jones supported planning and led carrying out of the study as principle investigator, as well as contributing to the write up and approving the final manuscript.,

\section{Ethics committee approval}

A statement is included in the manuscript, including the name of the committee granting approval.

\section{Clinical trial registration}

As this was not a clinical trial, no registration was obtained.

\section{Details of funding}

Blackpool Victoria Hospital (host organisation) provided a pump priming grant of $£ 6900$ to support this work internally. The department had no involvement in the carrying out or write up of the study, but did peer review the protocol before funding and as part of internal and ethics approval.

\section{Data sharing statement}

Original participant anonymised data is available from the authors on request 


\section{References}

1. Kohn LT, Corrigan JM, Donaldson MS. To err is human: building a safer health system. Washington, DC, Institute of Medicine National Academies Press, 1999

2. Dornan T, Ashcroft D, Heathfield H et al. An in-depth investigation into causes of prescribing errors by foundation trainees in relation to their medical education: EQUIP study. 2009. http://www.gmcuk.org/FINAL_Report_prevalence_and_causes_of_prescribing_errors.pdf_28935150.pdf

3. Avery T, Barber N, Ghaleb M et al. Investigating the prevalence and causes of prescribing errors in general practice: The PRACtICe Study. May 2012. http://www.gmc-

uk.org/Investigating the_prevalence_and_causes_of_prescribing_errors_in_general_practice_The_P $\underline{\text { RACtICe_study_Reoprt_May_2012_48605085.pdf }}$

4. National Patient Safety Agency. Data report oct 2014 - September 2015. 2015. http://www.nrls.npsa.nhs.uk/EasySiteWeb/getresource.axd?AssetID=135611\&type=full\&servicetype= $\underline{\text { Attachment }}$

5. Ross S, Loke YK. Do educational interventions improve prescribing by medical students and junior doctors? A systematic review. Br J Clin Pharmacol 2009;67:662-670

6. Gordon M, Box H, Halliwell JA, et al. Enhancing health care non-technical skills: the TINSELS programme. Clin Teach 2015;12: 413-417. doi:10.1111/tct.12433

7. Ross S, Bond C, Rothnie H, et al. What is the scale of prescribing errors committed by junior doctors? A systematic review Br J Clin Pharmacol 2009;67:629-640.

8. Catchpole K. Spreading human factors expertise in healthcare: untangling the knots in people and systems. BMJ Qual Saf 2013;22:793-797 doi:10.1136/bmjqs-2013-002036

9. Gordon M. Developing healthcare non-technical skills training through educational innovation and synthesis of educational research. 2014.

http://usir.salford.ac.uk/30826/1/M_GORDON_THESIS_FINAL_AMMENDED_FULL_SUBMISSIO $\underline{\text { N.pdf }}$

10. Donyai P, O'Grady K, Jacklin A, et al. The effects of electronic prescribing on the quality of prescribing. Br J Clin Pharmacol 2008;65:230-237

11. Cresswell K, Mozaffar H, Lee L, et al. Safety risks associated with the lack of integration and interfacing of hospital health information technologies: a qualitative study of hospital electronic prescribing systems in England. BMJ Qual Saf 2016;doi:10.1136/bmjqs-2015-004925.

12. Weiner EL, Nagel D. Human Factors in Aviation. New York: Academic Press. 1988

13. Lerner S, Magrane D, Friedman E.Teaching teamwork in medical education. Mt Sinai J Med 2009;76:318-29.

14. Dunn EJ, Mills PD, Neily J, et al. Medical team training: applying crew resource management in the Veterans Health Administration. Jt Comm J Qual Patient Saf 2007 Jun;33(6):317-25.

15. Gordon M, Baker P, Catchpole K, et al. Devising a consensus definition and framework for nontechnical skills in healthcare to support educational design: A modified Delphi study. Med Teach 2015;37(6):572-7.

16. Gordon M. Safety and Medical Devices: The Human Factors Perspective. Chapter in Surgical Tools and Medical Devices. Springer international publishing, Switzerland. 2016.

17. Gordon, M. Building a theoretically grounded model to support the design of effective nontechnical skills training in healthcare: The SECTORS model. J Contemp Med Edu 2013;1(2): 77-82 
18. Arora VM, Johnson JK,Meltzer DO, et al. A theoretical framework and competency-based approach to improving handoffs. Qual Saf Health Care 2008;17;11-14.

19. Caldwell G. Real Time "Check And Correct” Of Drug Charts On Ward Rounds - A Process For Improving Doctors' Habits In Inpatient Prescribing. Pharm Manag 2010;26:3-9.

20. Lépée C, Klaber RE, Benn J, et al. The use of a consultant-led ward round checklist to improve paediatric prescribing: An interrupted time series study. Eur J Pediatr 2012;171: 1239. doi:10.1007/s00431-012-1751-3

21. Wilson BB. Myers KM. Situated Cognition in Theoretical and Practical Context. In D. Jonassen, \& S. Land (Eds.) Theoretical Foundations of Learning Environments. Mahway, NJ: Lawrence Erlbaum Associates. 2000.

22. Gordon, M., Bose-Haider, B. A novel system of prescribing feedback to reduce errors: A pilot study. Int J Risk Saf Med, 2012;1:207-14

23. Hemming k, Girling AJ, Sitch AJ, et al. Sample size calculations for cluster randomised controlled trials with a fixed number of clusters. BMC Med Res Method 2011:102 DOI: 10.1186/1471-2288-11102

24. Wong ICK, Wong IYI, Cranswick NE. Minimising medication errors in children. Arch Dis Child 2009;94:161-4.

25. Dean Franklin B, Vincent C, Schachter M, et al. The Incidence of Prescribing Errors in Hospital Inpatients: An Overview of the Research Methods. Drug Saf 2005;28:891-900 


\section{Figure Legends}

Figure 1. Example of prescribing feedback provided 
